О1 основы топического лекарственного препарата: выбор оптимального значения и роль буферной системы

А.С. Духанин

ГБОУ ВПО «Российский национальный исследовательский медицинский университет им. Н.И. Пирогова» Минздрава России

127994, г. Москва, Рахмановский пер., д. 3

При выборе оптимального значения рН топического лекарственного препарата должны учитываться три группы фракторов: фрармацевтические, фрармакологические и фракторы совместимости. Для поддержания стабильного значения рН в основу препарата вводят различные бусерные системы, которые разделяются на монокомпонентные и двухкомпонентные. На примере топических препаратов, содержащих глюкокортикостероиды, рассмотрены оптимальные условия выбора и поддержания рН основы.

Ключевые слова: основа препарата, рН, буферная система, комбинированные топические препараты.

\title{
$\mathrm{PH}$ of the topical drug vehicle: selecting an optimum value and role of the buffer system
}

\section{A.S. Dukhanin}

Pirogov Russian National Research Medical University

Rakhmanovsky per., 3, Moscow, 127994, Russia

The following three groups of factors must be taken into consideration for selecting an optimum pH value of a topical drug: pharmaceutical, pharmacological and compatibility factors. To ensure a stable pH value, the drug vehicle comprises different buffer systems: single component and two-component ones. The optimum conditions for selecting and maintaining the vehicle pH were examined by the example of glucocorticosteroid-based topical drugs.

Key words: drug vehicle, pH, buffer system, combination topical drugs.

Corresponding author: das03@rambler.ru. Vestnik Dermatologii i Venerologii 2016; 2: 110_114. 
Важным фрактором эффрективности топического препарата является показатель $\mathrm{pH}$. На выбор оптимального значения $\mathrm{pH}$ для топического препарата одновременно влияют несколько фракторов:

ш оптимальный диапазон рН для сохранения фризической стабильности основы препарата;

- оптимальный диапазон $\mathrm{pH}$ для сохранения химической целостности действующих веществ (фармакологически активных соединений);

- оптимальный уровень $\mathrm{pH}$ для связывания активного вещества со своими молекулярными мишенями действия (кожа, бактерии, грибы) и проявления фармакологических свойств - противовоспалительного, антиаллергического, противозудного и антиэкссудативного эфрфектов, антибактериального или фунгицидного действия;

- соответствие $\mathrm{pH}$ наружного средства кислотности поверхности кожи.

В общем виде при выборе оптимального значения pH топического лекарственного препарата учитываются три группы фракторов: фармацевтические, фрармакологические и фракторы совместимости (рис. 1). Последовательно остановимся на каждом из них.

\section{Фармацевтические факторы}

Стабильность активного вещества, способность к длительному хранению без гидролиза, других химиче- ских реакций, разрушающих действующее начало препарата, напрямую зависят от значения $\mathrm{pH}$ основы препарата. Количественным критерием служит величина $\mathrm{pK}$ фрармакологического вещества, оптимальное значение $\mathrm{pH}$ препарата не должно сильно отличаться от $\mathrm{pK}_{\mathrm{a}}$, так как это способствует снижению растворимости, нестабильности и химическому разрушению активных ингредиентов [1]. Так, для бетаметазона дипропионата оптимальный диапазон рН составляет 5,0-7,0 [2].

В случае комбинированных препаратов в расчет принимаются оптимальные условия для сохранения химической стабильности всех входящих в состав препарата активных компонентов. Например, для препарата Тридерм - это глюкокортикостероид бетаметазона дипропионат, антимикотик клотримазол и антибиотик с бактерицидным эффректом гентамицин.

\section{Фармакологические факторы}

Действующее начало наружных препаратов глюкокортикостероиды, антибиотики, антимикотики - являются таргетными лекарственными веществами (от англ. target - мишень). Для проявления их противовоспалительной, антибактериальной или антимикотической активности лекарственное вещество должно найти и прочно связаться со своими молекулярными мишенями действия, расположенны-

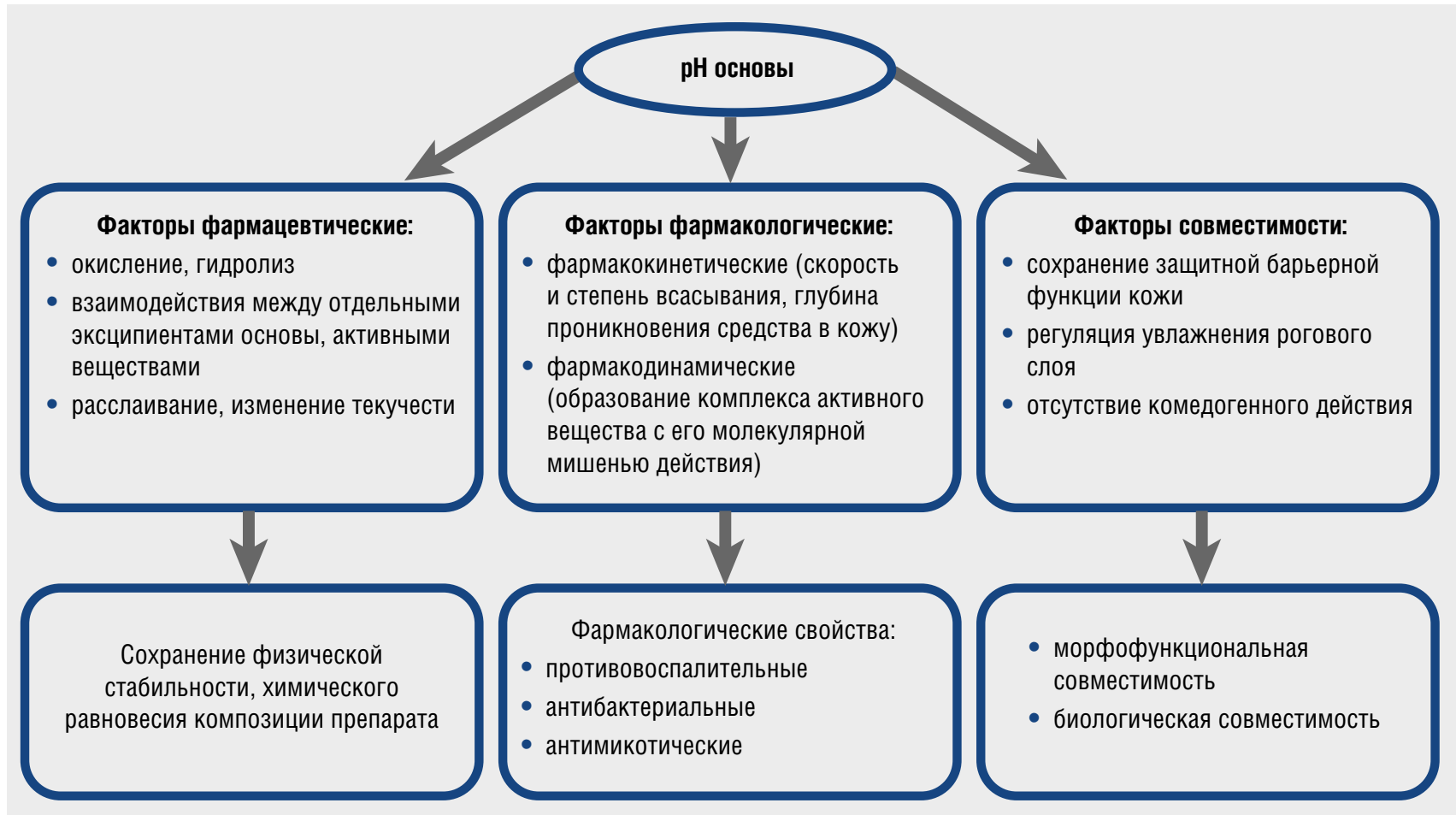

Рис. 1. Факторы, определяющие выбор оптимального значения рН основы топического препарата 
ми в коже (внутриклеточные рецепторы глюкокортикоидных гормонов), в бактериальной или грибковой клетках. Эффрективность образования комплекса лекарственного вещества и мишени, а следовательно, терапевтическая эффективность препарата, может меняться в зависимости от рН. Так, для антибиотиков из группы аминогликозидов и макролидов показано достоверное снижение бактерицидной активности при уменьшении рН. Кислая среда существенно повышает МИК (минимальную ингибирующую концентрацию), т.е. требует увеличения дозы антибиотика для проявления эквивалентной эффективности [3, 4]. Кислое значение $\mathrm{pH}(<7,0)$ драматически снижает активность гентамицина: МИК при рН 5,0 в 70 раз выше, чем при $\mathrm{pH} \mathrm{7,4} \mathrm{[5].} \mathrm{Оптимальный} \mathrm{уровень} \mathrm{pH}$ для проявления антимикробных свойств антибиотиков, используемых в наружной терапии: для эритромицина $\mathrm{pH} 7,5-8,0$; для неомицина - $\mathrm{pH} 5,5-6,0$; нитрофрурантоина - $\mathrm{pH}$ 6,0; для стрептомицина - $\mathrm{pH} 7,5-8,0$.

Получены сведения, что антимикотический эфрфект препаратов менее выражен при кислом значении $\mathrm{pH}$, адгезия клеток Candida максимальна при $37^{\circ} \mathrm{C}$ и рН 6,0 [6].

Следовательно, эффрективность составных компонентов топического препарата, чувствительных к изменению $\mathrm{pH}$, зависит как от кислотности места их действия (поверхность кожи, эпидермис, дерма, гиподерма), так и от рН наружного средства.

\section{Факторы совместимости кожи и основы препа-} рата

Учитывают такие параметры, как сохранение защитной и барьерной функции кожи, регуляция гидратации рогового слоя, отсутствие комедогенного действия, отсутствие аллергических реакций, соответствие $\mathrm{pH}$ наружного средства кислотности поверхности кожи [7]. Морфофункциональная совместимость топического препарата включает способность сохранять текстуру кожи, отсутствие комедогенного действия. Биологическая совместимость отражает свойства основы хорошо впитываться в кожу, не вызывать жирного блеска, быть удобной в применении, соответствовать рН водно-липидной мантии, учитывать возможность развития окклюзионного эфрфекта. вия:

$\mathrm{pH}$ поверхности кожи создает оптимальные усло-

для жизнеспособности клеток эпидермиса;

для осуществления защитных свойств рогового слоя, в частности антимикробного свойства;

для поддержания барьерных функций рогового слоя.

рН поверхности кожи - важная физиологическая константа, наравне с температурой, концентрацией глюкозы и кислорода она свидетельствует о состоянии гомеостаза в организме. Отклонение значения $\mathrm{pH}$ может указывать на развитие патологических процес- сов в коже [8]. Так, повышение $\mathrm{pH}$ наблюдается при атопическом дерматите (увеличение $\mathrm{pH}$ в среднем 0,5 ед.), контактном дерматите, у больных микозами (рН кожи стоп). Показана корреляция между тяжестью заболевания и изменением рН поверхности кожи [9].

Уровень рН напрямую определяет активность водородных связей, которые влияют:

на активность ферментов $\beta$-глюкоцереброзидазы и кислой сфингомиелиназы - ключевых ферментов, участвующих в регуляции проницаемости кожи [10];

механизмы трансмембранного транспорта - систему антипорта $\mathrm{Na}^{+} / \mathrm{H}^{+}$в мембранах ламеллярных структур рогового слоя эпидермиса [11];

пространственное строение сложноорганизованных структур, напрямую зависящих от рН, - ДНК, биополимеров - клеточных мембран, везикул, бислойных структур водно-липидной мантии [12];

антибактериальные свойства поверхности кожи (рис. 2).

Рост нормальной микробиоты кожи происходит при кислых значениях рН, в то время как для колонизации патогенных бактерий, таких как $S$. aureus, оптимальным является нейтральное значение $\mathrm{pH}$. Дермицидин, антимикробный пептид, отвечает за антимикробную активность секрета потовых желез в отношении различных патогенных микроорганизмов. При инкубации $S$. aureus c фрракцией пота, содержащей дермицидин, бактерицидный эффрект снижался с 90\% в буфрере с рH 5,5 до 60\% в буфере с рH 6,5 [13]. Также отмечено снижение антибактериальной активности катионных биологически активных веществ, например некоторых основных белков, вследствие уменьшения кислотности поверхности кожи. Нитраты, которые вырабатываются в потовых железах, метаболизируются бактериями до нитритов. Последние служат неспецифическим антибактериальным защитным механизмом, который активен при кислой реакции среды [14].

Ингибитор сериновых протеаз белок LEKTI считается ключевым рН-зависимым регулятором десквамации [15]. Первоначальные представления о том, что кислая реакция рогового слоя фрормируется за счет экзогенных источников (продукты жизнедеятельности микроорганизмов, свободные жирные кислоты, содержащиеся в секрете сальных желез, и такие продукты эккринных потовых желез, как аминокислоты и молочная кислота), пополнились данными последних лет. Дополнительными источниками кислой реакции мантии кожи служат эндогенные субстраты, в частности промежуточные продукты, образующиеся в ходе процессов кератинизации, синтез свободных жирных кислот при гидролизе фоссролипидов секреторной фосфолипазой А2 и энергонезависимый $\mathrm{Na}^{+} / \mathrm{H}^{+}-$обмен [16].

\section{Буферная система топического препарата}

Недостаточно выбрать оптимальный уровень $\mathrm{pH}$ основы топического препарата, необходимо его удер- 


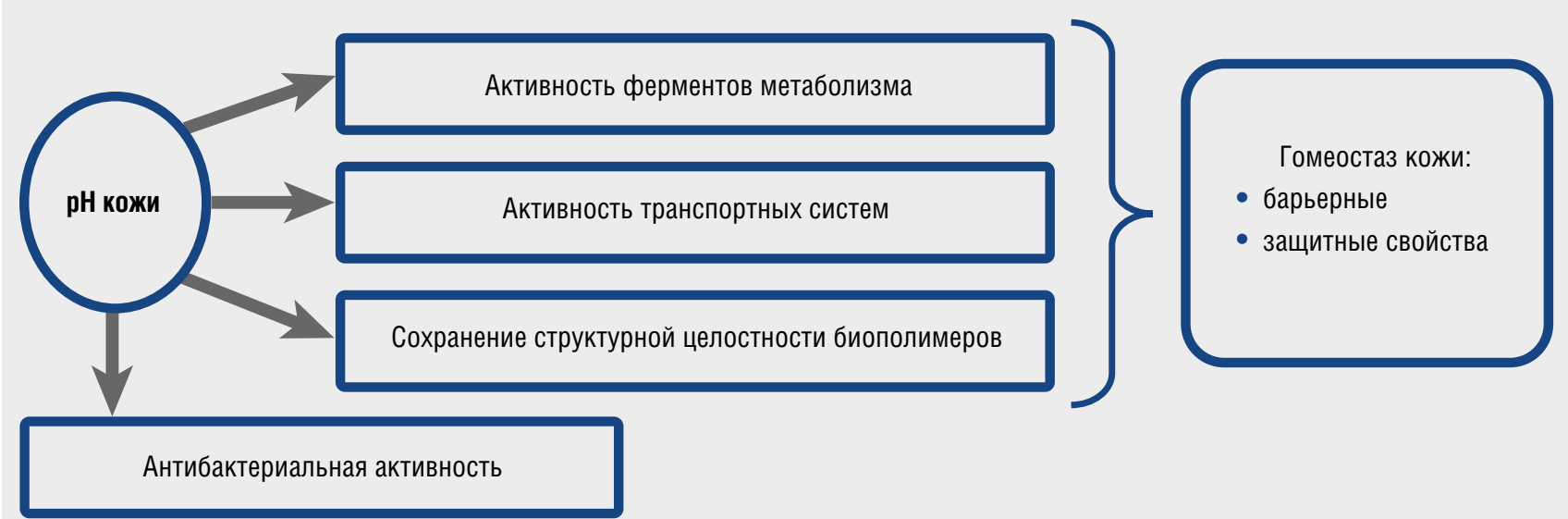

Рис. 2. Роль рН в гомеостазе кожи

жать. Для поддержания $\mathrm{pH}$ в заданном интервале значений применяются буферные системы - одно или несколько химических соединений со специальными свойствами, способные поддерживать заданную концентрацию ионов водорода $\mathrm{H}^{+}$.

Для поддержания определенной концентрации ионов водорода, т.е. определенной кислотности основы, в состав топических препаратов дополнительно вводят буферные системы.

В зависимости от химической природы буферные системы делят:

па однокомпонентные (содержат одно соединение);

двухкомпонентные (содержат два активных соединения).

Двухкомпонентные системы имеют более высокую буферную емкость, т.е. повышенную способность удерживать $\mathrm{pH}$ в заданном диапазоне.

Активизация фрлоры на фроне применения топических глюкокортикостероидов является одним из факторов, ограничивающих как назначение, так и сроки применения [7]. В связи с этим особого внимания заслуживают основы глюкокортикостероидов, в состав которых включены буферные системы. В таблице приведены примеры буферных систем топических препаратов, содержащих глюкокортикоиды.

Добавление фосфорной кислоты как второго компонента буферной системы значительно повышает буферную емкость, ее сопротивление изменению $\mathrm{pH}$ среды в щелочную сторону.

Более разнообразный состав буферной композиции в креме Тридерм, введение в ее состав второго компонента - фросфорной кислоты - способствует повышению антимикробных свойств поверхности кожи, что свидетельствует в пользу лекарственной фрормы препарата Тридерм.

\section{Природные буферные системы кожи}

Поверхность кожи в норме имеет кислую реакцию - в диапазоне значений $\mathrm{pH} 4,0-6,0$, в то время как внутренняя среда организма поддерживается на уровне, близком к нейтральным величинам (pH 7,0-7,5). Это является причиной выраженного градиента $\mathrm{pH}$ (2-3 ед.) между $\mathrm{pH}$ рогового слоя и $\mathrm{pH}$ эпидермиса и дермы [10]. Повышение уровня рН способствует росту активности сериновой протеазы, калликреина 5 и 7 (KLK 5, 7), которые участвуют в десквамации и деградации корнеодесмосом [17].
Монокомпонентная буферная система

Натрия дигидрофоссрат дигидрат (Акридерм ГК, крем)

Фоссрорная кислота (Элоком, крем)
Двухкомпонентная буферная система

Натрия дигидросоосфат дигидрат и фосфорная кислота (Тридерм, крем)

Однозамещенный фоссрат натрия, безводный фоссоорнокислый натрий (Кандид Б, крем) 
Основными природными буферными системами внутриклеточной и межклеточной жидкости кожи являются бикарбонатная, фоссратная и белковая буфрерные системы. Величина рН возрастает в направлении клетка - межклеточная среда - кровь. Таким образом, наибольшую буферную емкость имеет кровь, а наименьшую - внутриклеточная среда. Образуемые в клетках при метаболизме кислоты поступают в межклеточную жидкость тем легче, чем больше их образуется в клетках, так как избыток ионов водорода повышает проницаемость клеточной мембраны. В буферных свойствах межклеточной среды играет роль соединительная ткань, особенно коллагеновые волокна. На минимальное накопление кислот они реагируют набуханием, связывая ионы водорода межклеточной жидкости.
Итак, оптимальное значение $\mathrm{pH}$ основы топического препарата определяется составом основы и входящих в него фармакологически активных веществ, а также соответствием рН поверхности кожи. Поддержание $\mathrm{pH}$ основы препарата обеспечивает буферная система, которая может быть представлена одним (монокомпонентная) или двумя компонентами (двухкомпонентная). Двухкомпонентные системы имеют более высокую буфрерную емкость, т. е. повышенную способность удерживать рН в заданном диапазоне. Добавление фосфорной кислоты как второго компонента буферной системы, с одной стороны, повышает ее сопротивление изменению pH кожи в щелочную сторону, с другой - способствует повышению антимикробных свойств поверхности кожи. I

\section{Литература}

1. Shargel L., Wu-Pong S., Yu A.B.C. Applied biopharmaceutics \& pharmacokinetics. Fifth edition. California, McGraw-Hill Companies, 2007.

2. Khattak S.U.R., Sheikh D., Ahmad I., Usmanghani K. Kinetics of thermal degradation of betamethasone valerate and betamethasone dipropionate in different media. Indian J Pharm Sci. 2012; 74 (2): 133-140.

3. Simmen H.P. et al. Effect of peritoneal fluid pH on outcome of aminoglycoside treatment of intraabdominal infections. World J Surg 1993; 17: 393-7.

4. Barcia-Macay M. et al. Pharmacodynamic evaluation of the intracellular activities of antibiotics against Staphylococcus aureus in a model of THP-1 macrophages. Antimicrob Agents Chemother 2006; 50: 841—51.

5. Pierre Baudoux et al. Combined effect of $\mathrm{pH}$ and concentration on the activities of gentamicin and oxacillin against Staphylococcus aureus in pharmacodynamic models of extracellular and intracellular infections J. Antimicrob. Chemother. 2007; 59 (2): 246-253.

6. Kuipers M.E. Conditions influencing the in vitro antifungal activity of lactoferrin combined with antimycotics againstclinical isolates of Candida. APMIS. 2002; 110: 290—298.
7. Araviyskaya E.R., Sokolovskiy E.V., Bahtina S.M., Pchelintsev M.V. Rol osnovyi v glyukokorikosteroidnyih preparatah: optimalnyiy sostav i mehanizm deystviya. Vestn dermatol venerol 2010; 2: 64-70. [Аравийская Е.Р., Соколовский Е.В., Бахтина С.М., Пчелинцев М.В. Роль основы в глюкокорикостероидных препаратах: оптимальный состав и механизм действия. Вестн дерматол венерол 2010; 2: 64-70.]

8. Schmid-Wendtner M.H., Korting H.C. The pH of the skin surface and its impact on the barrier function. Skin Pharmacol Physiol 2006; 19 (6): 296-302.

9. Rizi K., Green R.J., Donaldson M.X. and Williams A.C. Using $\mathrm{pH}$ abnormalities in diseased skin to trigger and target topical therapy. Pharmaceutical Research 2011; 28 (10): 2589_ 2598.

10. Ali S.M., Yosipovitch G. Skin pH: From Basic Science to Basic Skin Care. Acta Derm Venereol 2013; 93: 261-267.

11. Behne M.J., Meyer J.W., Hanson K.M., Barry N.P., Murata S., Crumrine D., Clegg R.W., Gratton E., Holleran W.M., Elias P.M., Mauro T.M. NHE1 regulates the stratum corneum permeability barrier homeostasis. Microenviron- ment acidification assessed with fluorescence lifetime imaging. J Biol Chem 2002; 277 (49): 47399_47406.

12. Elias P.M. Structure and Function of the Stratum Corneum Extracellular Matrix. J Invest Dermatol 2012; 132 (9): 2131-2133.

13. Schittek B., Hipfel R., Sauer B., Bauer J., Kalbacher H., Stevanovic S. Dermicidin: a novel human antibiotic peptide secreted by sweat glands. Nat Immunol 2001; 2: 1133-1137.

14. Weller R., Price R.J., Ormerod A.D. Antimicrobial effect of acidified nitrite on dermatophyte fungi, Candida and bacterial skin pathogens. J Appl Microbiol 2001; 90: 648—652.

15. Thomas Hubiche T., Ged C., Benard A. Analysis of SPINK 5, KLK 7 and FLG Genotypes in a French Atopic Dermatitis Cohort. Acta Derm Venereol 2007; 87: 499-505.

16. Panther D.J., Jacob S.E. The Importance of Acidification in Atopic Eczema: An Underexplored Avenue for Treatment. J Clin Med 2015; 4 (5): 970-8.

17. Ekholm E., Brattsand M., Egelrud T. Stratum comeum tryptic enzyme in normal epidermis: A missing link in the desquamation process? J Invest Dermatol 2000; 114: 56—63.

об авторе:

А.С. Духанин - д.м.Н., профессор, профессор кафедры молекулярной фармакологии и радиобиологии ГБОУ ВПО РНИМУ им. Н.И. Пирогова Минздрава России, Москва

\section{Конфликт интересов}

Автор заявляет об отсутствии потенциального конфликта интересов, требующего раскрытия в данной статье 